\title{
Removal of Yellow 2G dye from aqueous solutions using activated carbon prepared from mosambi and cotton an agricultural waste
}

\author{
U. V. Ladhe, P. R. Patil \\ School of Environmental and Earth Sciences, North Maharashtra University, Jalgaon- 425 001, MS, India
}

\begin{abstract}
Adsorption of Yellow $2 G$ from aqueous solution on the surface of Activated carbon of mosambi peel (ACMP) and stem of cotton (ACCS) was accomplished under the optimize conditions of pH, adsorbent dose, initial concentration of dye and contact time. Spectrometric technique was used for the measurements of concentration of dye before and after adsorption. Colour was effectively been removed at all selected $\mathrm{pH}$, and the increase in activated carbon dose showed an increase in the removal's percentage. The result shows that the removal efficiency increases with adsorbents dose increases and at neutral $\mathrm{pH}$. The equilibrium data fit well with both Langmuir and Freundlich models of adsorption. The value of separation factor $R_{L}$ for ACMP and ACCS was found to be 0.135 and 0.080 respectively suggesting that the isotherm to be favorable at the concentration studied. The results of findings are discussed to reflect the removal efficiency of adsorbent.

Keywords: Yellow 2 G, Mosambi Peels, and Stem of Cotton, Adsorption, Langmuir and Freundlich isotherm.
\end{abstract}

\section{INTRODUCTION}

Dyes production industries and many others industries which used dyes and pigments generated wastewater, characteristically high in colour and organic content. Most of the industries such as textile, paper, carpet, and printing use dyes and pigments to color their products. Due to their good solubility, synthetic dyes are common water pollutants and they may frequently be found in trace quantities in industrial wastewater. However, the discharge of dye-bearing wastewater into natural streams and rivers possess a severe problem, as dyes impart toxicity to aquatic life and are damaging the aesthetic nature of the environment. In order to preserve the physical and ecological properties of the receiving water bodies and the environment it is necessary to remove dyes from waste water. Among various physical and chemical methods used for removal of dyes, adsorption has shown better decontamination efficiencies. Activated carbons are widely known for their high absorption capacity, however, high operating cost hamper their use in large scale applications [1]. This has prompted many researchers to search for cheaper substitutes such as babul Seed [2], barley husk [3], sunflower stalks [4] and the peel of cucumis sativa fruit [5], orange peel and lemon peel [6] were used as adsorbent. Consequently, a low cost and easily available material such as mosambi peels can be studied for the removal of different dyes from aqueous solutions at different operating conditions. Mosambi was easily available fruit in local area in bulk quantity and its peels were used to prepare adsorbent for the dye removal. Previously the work on removal of textile Erichrome black $\mathrm{T}$ dye from aqueous solution from aqueous solution by adsorption technique using natural waste was investigated in this laboratory. [7-9] In the present investigation, we used mosambi peels and stems of cotton as a raw material to produce activated carbon to remove the Yellow $2 \mathrm{G}$ dye from water.

\subsection{Adsorbate}

\section{MATERIALS AND METHOD}

Stock solution $(1000 \mathrm{mg} / \mathrm{l})$ of Yellow 2G Dye was prepared by dissolving $1 \mathrm{~g}$ of dye in $1000 \mathrm{~mL}$ of double distilled water. The stock solutions were diluted with double distilled water to obtain required standard solution..$^{92}$ Batch adsorption studies were performed at room temperature $\left(39 \pm 1^{\circ} \mathrm{C}\right)$. TABLE 1 enlists the properties of Yellow 2G Dye used. .

\subsection{Adsorbents}

The mosambi peels and stems of cotton were collected from local area of Jalgaon district in clean plastic bags. These waste materials are washed with distilled water, dried in sunlight, then $60^{\circ} \mathrm{C}$ for 24 hours in hot air oven. The dried material was subjected for acid treatment (ratio 1:1) and kept at room temperature overnight and stored in a tight lid container for further studies. It is then screened through a mesh sieve with a particle size range of 180-300 $\mu \mathrm{m}$. Carbon was prepared by treating air-dried prepared fresh natural adsorbents with concentrated sulphuric acid in a weight ratio of 1:1 for 24 hours. The resulting black product was kept in an air-oven maintained at $105^{\circ} \mathrm{C}$ for 12 hours followed by washing with $\mathrm{NaHCO}_{3}$ and water until free from excess acid and dried at $105 \pm 5^{\circ} \mathrm{C}$ to get mosambi peel activated carbon and activated carbon of stem of cotton. Product 
obtained was ground well to fine powder and the physical properties are analyzed by usual standard methodologies.

\subsection{Batch adsorption studies}

Adsorption experiments were performed at room temperature $\left(39 \pm 1^{\circ} \mathrm{C}\right), 0.004 \mathrm{~g} / \mathrm{ml}$ of adsorbent was mixed with known initial dye concentration (50,100, 150, 200 and $250 \mathrm{mg} / \mathrm{l}$ respectively) $100 \mathrm{mg} / \mathrm{l}$ dye solution was used for adsorbent dose variation study. For $\mathrm{pH}$ variation, $100 \mathrm{mg} / \mathrm{l}$ dye solution with $0.004 \mathrm{~g} / 1$ adsorbent dose was used. The adsorbent and adsorbate were separated by filtration and filtrate was analysed for residual Yellow 2G concentration spectrophotometrically using UV Visible spectrophotometer (Systronic, Model No. 166) at $\lambda_{\max }=340 \mathrm{~nm}$.

\section{RESULTS AND DISCUSSION}

\subsection{Characteristics of the adsorbent}

The physico- chemical properties of the prepared activated carbon were determined by standard procedures. Surface area was determined by BET method. The physico- chemical properties are listed in TABLE 2.

\subsection{Effect of Dye Concentration:}

To study the effect of different initial concentrations of Yellow $2 \mathrm{G}$ on adsorption behaviour, five concentrations $(50,100,150,200$ and $250 \mathrm{mg} / \mathrm{L}$ ) were used and the amounts adsorbed were calculated and given in TABLES 3-4. The observed increase in the adsorption of Yellow $2 \mathrm{G}$ with increase in concentration may be due to sufficient adsorption sites at adsorbent. The amount of dye adsorbed $(\mathrm{mg} / \mathrm{g}$ ) increased with increase in time and the equilibrium for dye removal attainment was achieved after $120 \mathrm{~min}$. The initial dye concentration provides the necessary driving force to overcome the resistances to the mass transfer of Yellow $2 \mathrm{G}$ between the aqueous and solid phases. The maximum adsorption is obtained by ACMP and ACCS which is $88.78 \%$ and $92.14 \%$ respectively. [10]

\subsection{Effect of adsorbent dose variation:}

The effect of adsorbent dose on removal of yellow $2 \mathrm{G}$ was studied by varying the dose of adsorbent $(0.002$, $0.004,0.006,0.008$ and $0.01 \mathrm{~g} / \mathrm{L}$ ) in the test solution while keeping the initial dye concentration $100 \mathrm{mg} / \mathrm{L}$ (Temperature $39 \pm 1^{\circ} \mathrm{C}$ ) at $\mathrm{pH}=7$. Experiments were carried out at different contact times for 120 mins. Tables 3.22 - 3.27 reveal that percent of adsorption increased with increasing adsorbents doses. The increase in the percent removal of dye with the increase in adsorbent dosage is due to the availability of larger surface area with more active functional groups. The maximum adsorption yellow $2 \mathrm{G}$ is by ACMP and ACCS which is $92.68 \%$ and $94.12 \%$ respectively. [11]

\subsection{Effect of $\mathrm{pH}$ variation}

Adsorption is also affected by change in $\mathrm{pH}$ of the solution as shown in Fig 1. The hydrogen ion concentration $(\mathrm{pH})$ primarily affects the degree of ionization of the dye and the surface properties of the adsorbents. Experiments were carried out at $100 \mathrm{mg} / \mathrm{L}$ initial dye concentration with $0.004 \mathrm{~g} / \mathrm{L}$ adsorbent mass at room temperature $\left(39 \pm 1^{\circ} \mathrm{C}\right)$ for 3 hour equilibrium time. It is clear from the Fig 1 that for each initial concentration value of yellow $2 \mathrm{G}$, the percent removal increases as $\mathrm{pH}$ rises and after $\mathrm{pH}$ 7.0, the percent removal decreases with further increase in $\mathrm{pH}$ value. This clearly shows that the optimum $\mathrm{pH}$ for the present adsorbate-adsorbent system is 7.0.' [12]

\subsection{Adsorption Isotherm:}

The experimental data are analyzed according to the linear form of the Langmuir and Freundlich isotherms. The Langmuir isotherm is represented by the following equation

$(\mathrm{Ce} / \mathrm{qe})=(1 / \mathrm{Qob})+(\mathrm{Ce} / \mathrm{Qo})$

Here Ce is the equilibrium concentration $(\mathrm{mg} / \mathrm{L})$, qe is the amount adsorbed at equilibrium $(\mathrm{mg} / \mathrm{g})$. Qo and $\mathrm{b}$ is Langmuir constants related to the adsorption efficiency and energy of adsorption, respectively. [13]

The linear plots of Ce/qe versus Ce suggest the applicability of the Langmuir isotherms are given in Figures 2 and 4 for ACMP and ACCS respectively. The values of Qo and b were determined from slope and intercepts of the plots and are presented in TABLE 7.

The essential characteristics of the Langmuir isotherm can be expressed in terms of a dimensionless constant separation factor RL that is given in Eq.2.

$\mathrm{R}_{\mathrm{L}}=1 /(1+\mathrm{bCo}) \quad$---------- (2) 
The value of RL indicates the type of the isotherm to be either favorable $(0<R L<1)$, unfavorable $(\mathrm{RL}>$ $1)$, linear $(R L=1)$ or irreversible $(R L=0)$. The value of $R L$ was found to be the values of $R L$ were found between 0 and 1 for ACMP and ACCS suggesting the isotherm to be favorable at the concentrations studied. [14]

The Freundlich equation is also employed for the adsorption of Poly Acid Brill Red 3 BN on the ACMP and ACCS adsorbent. The Freundlich isotherm (Freundlich, 1906) is represented as

$\log \mathrm{qe}=\log \mathrm{kf}+(1 / \mathrm{n}) \log \mathrm{Ce}$

Here qe is the amount of yellow $2 \mathrm{G}$ dye adsorbed $(\mathrm{mg} / \mathrm{g})$, Ce is the equilibrium concentration of dye in the solution $(\mathrm{mg} / \mathrm{L})$ and $\mathrm{Kf}$ and $\mathrm{n}$ are constants incorporating all factors affecting the adsorption capacity and intensity of adsorption, respectively. Linear plot of $\log$ qe versus $\log$ Ce shows that the adsorption of yellow $2 \mathrm{G}$ follows also the Freundlich isotherm (Figure 3 and 5 for ACMP and ACCS respectively). The values of Kf and $\mathrm{n}$ given in the Table 7. As seen from Table 7, the increase in negative charges on the adsorbent surface that makes electrostatic forces like Vander Waals between the adsorbent surface and dye ion. The molecular weight, size and radii either limit or increase the possibility of the adsorption of the dye onto adsorbent. However, the values clearly show the dominance in adsorption capacity. The intensity of adsorption is an indicative of the bond energies between dye and adsorbent and the possibility of slight chemisorptions rather than physisorption. However, the multilayer adsorption of yellow $2 \mathrm{G}$ through the percolation process may be possible. The ' $n$ ' value was 1.9305 and 2.1739 was in between 1 and 10 indicating the adsorption is much more favourable for a selected adsorbents. [15]

\section{FIGURES AND TABLES}

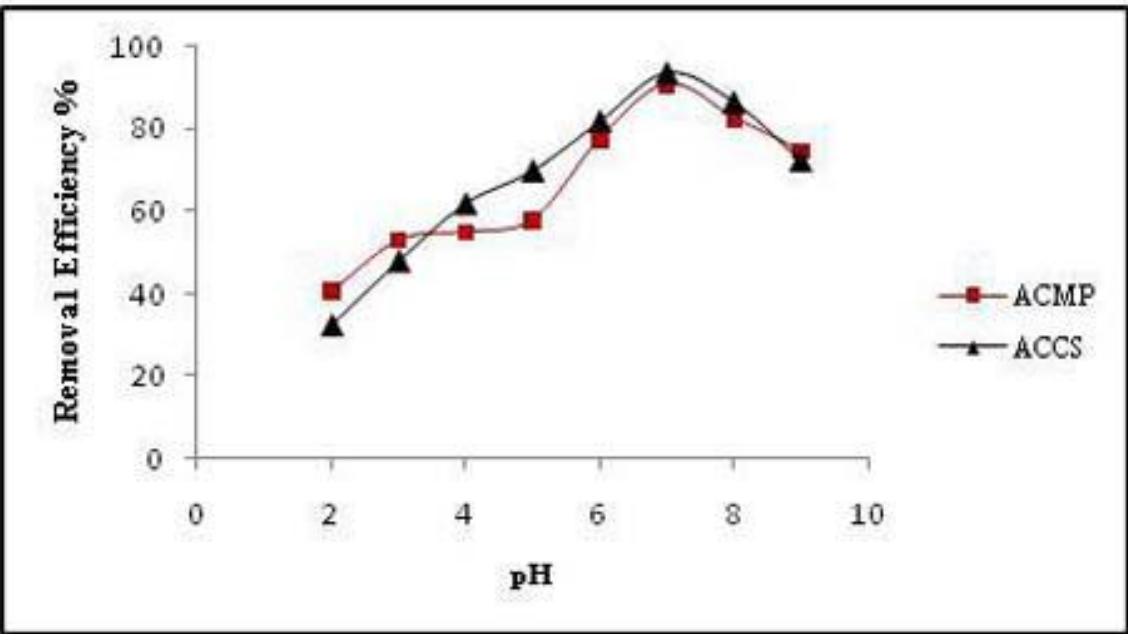

Figure 1 : Effect of $\mathrm{pH}$ on Yellow $2 \mathrm{G}$ removal

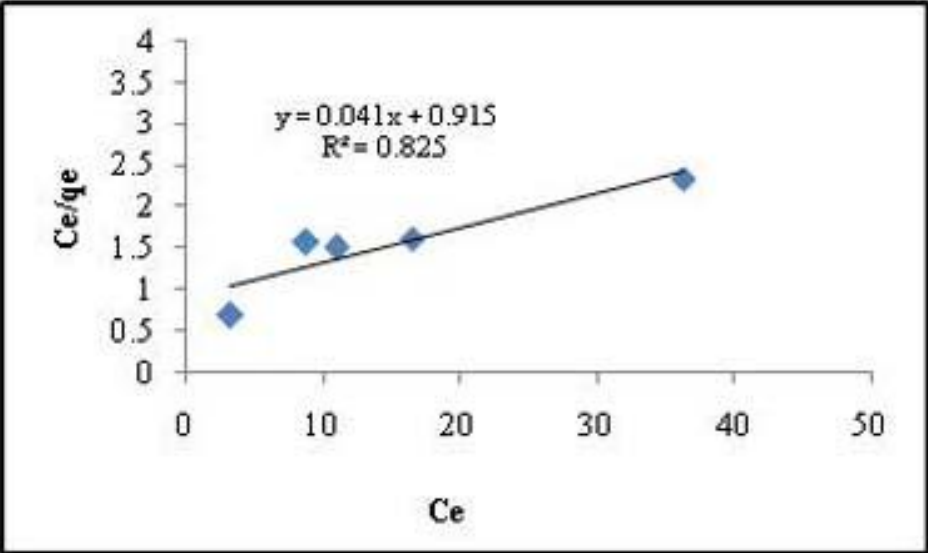

Figure 2: Langmuir isotherm for the removal of Yellow 2G by ACMP 


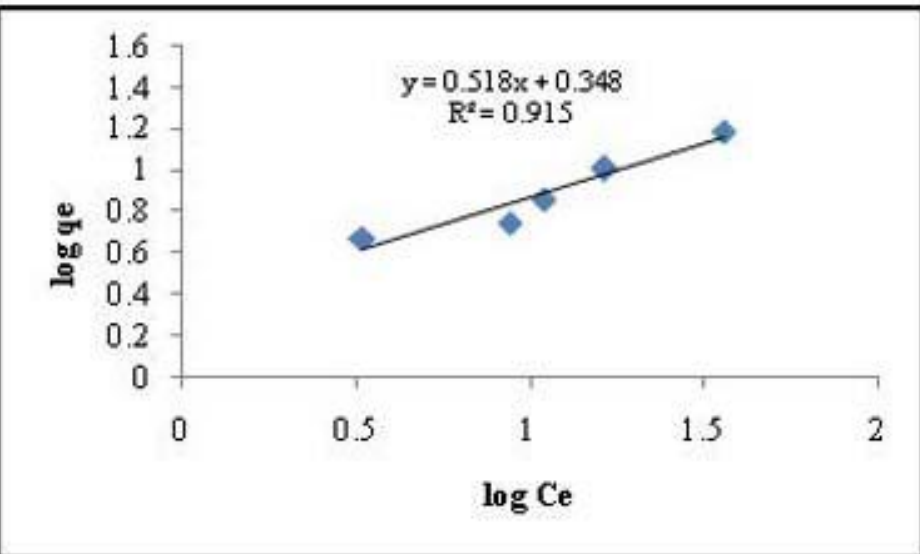

Figure 3: Freundlich isotherm for the removal of Yellow 2G by ACMP

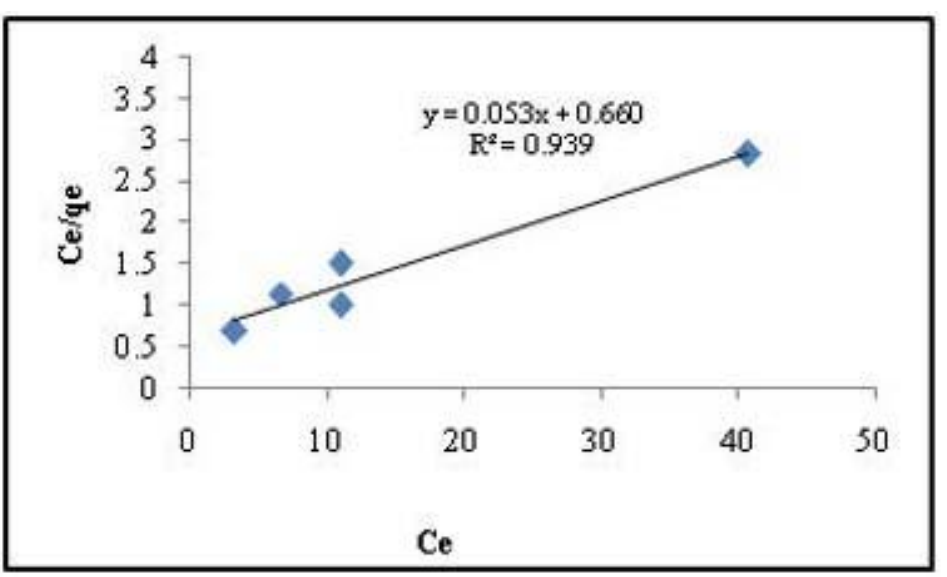

Figure 4: Langmuir isotherm for the removal of Yellow 2G by ACCS

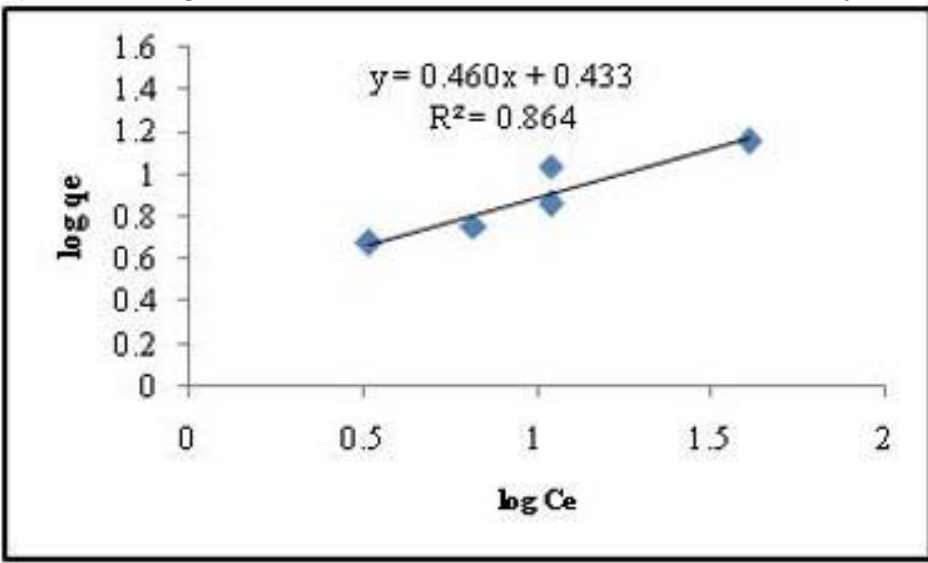

Figure 5: Freundlich isotherm for the removal of Yellow 2G by ACCS

TABLE 1 Characteristic of Yellow 2G Dye

\begin{tabular}{l|l}
\hline Molecular Formula & $\mathrm{C}_{16} \mathrm{H}_{10} \mathrm{Cl}_{2} \mathrm{~N}_{4} \mathrm{Na}_{2} \mathrm{O}_{7} \mathrm{~S}_{2}$ \\
CAS number & $6359-98-4$ \\
CI Number & 18965 \\
Water Solubility & $100 \mathrm{~g} / 1$ \\
\hline
\end{tabular}


TABLE 2: Characteristic of activated carbons of mosambi peels and stem of cotton.

\begin{tabular}{llcc}
\hline Sr No. & Prop exties & $\begin{array}{c}\text { Mosambi Peel } \\
\text { Activated Carbon }\end{array}$ & $\begin{array}{c}\text { Stem of Co tton } \\
\text { Activated Carbon }\end{array}$ \\
\hline 1 & pH & 7.7 & 7.3 \\
2 & Moisture Content (\%) & 6 & 7 \\
3 & Ash Content (\%) & 23 & 24 \\
4 & Apperent D ensity $\left(\mathrm{g} \mathrm{cc}^{-1}\right)$ & 0.5494 & 0.431 \\
5 & Solubility in water $(\%)$ & 0.34 & 0.54 \\
6 & Solubility in HC1 $(\%)$ & 0.89 & 1.78 \\
7 & Surface area $\left(\mathrm{m}^{2} \mathrm{~g}^{-1}\right)$ & 189 & 198 \\
\hline
\end{tabular}

TABLE 3: Effect of different initial dye concentration on dye removal using ACMP (Adsorbent dosage $=400 \mathrm{mg} / 50 \mathrm{~mL}$, initial $\mathrm{pH}=7.0$, time $=120 \mathrm{~min}$ size $=180-300$ micron $)$

\begin{tabular}{cllllll}
\hline \multirow{2}{*}{ Initial dye co ncentration $(\mathbf{m g} / \mathbf{L})$} & \multicolumn{6}{c}{ Percentage of dye removal with time (min) } \\
\cline { 2 - 7 } & 15 & 30 & 45 & 60 & 90 & 120 \\
\hline 50 & 26.42 & 49.06 & 56.60 & 73.58 & 86.79 & 88.68 \\
100 & 28.57 & 45.92 & 62.24 & 80.61 & 87.76 & 88.78 \\
150 & 32.14 & 48.57 & 65.00 & 78.57 & 87.86 & 88.57 \\
200 & 35.33 & 49.46 & 61.41 & 78.80 & 88.04 & 88.59 \\
250 & 38.01 & 53.85 & 60.18 & 76.92 & 88.24 & 88.69 \\
\hline
\end{tabular}

TABLE 4: Effect of different initial dye concentration on dye removal using ACCS (Adsorbent dosage $=400 \mathrm{mg} / 50 \mathrm{~mL}$, initial $\mathrm{pH}=7.0$, time $=120 \mathrm{~min}$. Size $=180-300$ micron $)$

\begin{tabular}{cllllll}
\hline \multirow{2}{*}{ Initial dye concentration $(\mathbf{m g} / \mathrm{L})$ ) } & \multicolumn{5}{l}{ Percentage of dye removal with time (min) } \\
\cline { 2 - 7 } & 15 & 30 & 45 & 60 & 90 & 120 \\
\hline 50 & 22.64 & 37.74 & 60.38 & 73.58 & 88.68 & 90.57 \\
100 & 24.49 & 39.80 & 57.14 & 72.45 & 88.78 & 89.80 \\
150 & 32.86 & 52.14 & 70.00 & 81.43 & 90.71 & 92.14 \\
\hline
\end{tabular}

TABLE 5: Effect of different concentration of ACMP on dye removal (Dye concentration= $100 \mathrm{mg} / \mathrm{l}$, initial $\mathrm{pH}=7.0$, time $=120 \mathrm{~min} .$, size $=180-300$ micron $)$

\begin{tabular}{cllllll}
\hline \multirow{2}{*}{ Ad sombent d ose $(\mathbf{g} / \mathbf{1 0 0} \mathbf{m L})$} & \multicolumn{6}{c}{ Pexcentage of d ye remov al with time (mim) } \\
\cline { 2 - 7 } & 15 & 30 & 45 & 60 & 90 & 120 \\
\hline 0.2 & 21.14 & 34.15 & 45.53 & 62.60 & 70.73 & 73.17 \\
0.4 & 28.57 & 45.92 & 62.24 & 80.61 & 84.69 & 84.69 \\
0.6 & 35.44 & 54.43 & 64.56 & 79.75 & 86.08 & 87.34 \\
0.8 & 41.79 & 59.70 & 76.12 & 82.09 & 88.06 & 88.06 \\
1 & 29.27 & 53.66 & 68.29 & 80.49 & 90.24 & 92.68 \\
\hline
\end{tabular}

TABLE 6: Effect of different concentration of ACCS on dye removal (Dye Concentration= $100 \mathrm{mg} / \mathrm{l}$, initial $\mathrm{pH}=7.0$, time $=120 \mathrm{~min} .$, size $=180-300$ micron $)$

\begin{tabular}{cllllll}
\hline \multirow{2}{*}{ Ad som ent d ose (g/100mL) } & \multicolumn{6}{c}{ Percentage of d ye removal with time (min) } \\
\cline { 2 - 7 } & 15 & 30 & 45 & 60 & 90 & 120 \\
\hline 0.2 & 20 & 19.13 & 25.22 & 46.96 & 66.09 & 67.83 \\
0.4 & 24.49 & 39.80 & 57.14 & 72.45 & 88.78 & 89.80 \\
0.6 & 24.36 & 47.44 & 61.54 & 75.64 & 87.18 & 87.18 \\
0.8 & 14.52 & 25.81 & 50.00 & 77.42 & 90.32 & 90.32 \\
1 & 27.45 & 43.14 & 58.82 & 78.43 & 92.16 & 94.12 \\
\hline
\end{tabular}

TABLE 7: Langmuir and Freundlich isotherm of activated carbon prepared from various materials for Yellow $2 \mathrm{G}$

\begin{tabular}{|c|c|c|c|c|c|c|c|}
\hline \multirow[t]{2}{*}{ Adsorbents } & \multicolumn{4}{|c|}{ L angmuir iso therm } & \multicolumn{3}{|c|}{ Freundlich iso therm } \\
\hline & $Q_{0}$ & b & $\begin{array}{c}\text { Correbtion } \\
\text { coefficient (r) }\end{array}$ & RL. & $\begin{array}{c}\text { Intercept } \\
\text { (kf) }\end{array}$ & $\begin{array}{l}\text { Slop e } \\
\text { (1/n) }\end{array}$ & $\begin{array}{c}\text { Correlation } \\
\text { coefficient (r) }\end{array}$ \\
\hline ACMP & 24.390 & 0.0448 & 0.825 & 0.135 & 0.348 & 0.518 & 0.915 \\
\hline $\mathrm{ACCS}$ & 18.867 & 0.0803 & 0.939 & 0.080 & 0.433 & 0.46 & 0.864 \\
\hline
\end{tabular}




\section{CONCLUSION}

The present study revealed that activated carbon prepared from natural waste like peels of mosambi and stem of cotton could be employed as a potential adsorbent for the removal of Yellow $2 \mathrm{G}$ dye. The adsorption of Yellow $2 \mathrm{G}$ was found to be dependent on the $\mathrm{pH}$, contact time, initial concentration and adsorbents dosage. The experimental data of Yellow $2 \mathrm{G}$ was analyzed according to the linear form of the Langmuir and Freundlich isotherms. The adsorption obeyed both Langmuir and Freundlich isotherms for selected adsorbents such as peels of Mosambi and stems of Cotton. The characteristic parameters for each isotherm and related correlation coefficients were determined from graphs of their linear equations. Both Langmuir and Freundlich isotherms were demonstrated to provide a meaningful correlation for the adsorption of dye on to activated carbon prepared from natural waste. The advantage is twofold; it not only acts as an effective and economic tool as compared to other existing commercial carbons for solving the problem of dye pollutions but also helps in an effective and useful disposal of natural waste from local area.

\section{REFERENCES}

[1] Ponnusami V., Krithika V., Madhuram, R. Srivasta, S. N., 2007, Biosorption of reactive dye using acid-treated rice husk: Factorial design analysis. Journal of Hazardous Materials, 142: 397-403.

[2] M Sujatha, A.Geetha, P.Sivakumar, and P. N.Palanisamy (2008). Orthophosphoric Acid Activated Babul Seed Carbon as an Adsorbent for the Removal of Methylene Blue, E- Journal of Chemistry 5(4), pp 742-753.

[3] Robinson T, Chandran B, Sathya Naidu G and Nigam P (2002). Studies on the removal of dyes from a synthetic textile effluent using barly husk in static-batch mode and in a continuous flow, packed -bed reactor. Bioresources Technology, 85, pp 43-49.

[4] Gang, Sun and Xu. Xiangjing (1997). Sunflower stalks as adsorbents for color removal from textile wastewater. Ind Eng Chem Res, 6, pp 808-812.

[5] Thirumalisamy S and Subbian M (2010). Removal of methylene blue from aqueous solution by activated carbon prepared from the peel of cucumis sativa fruit by adsorption. Bioresources, 5(1), pp 419-437.

[6] Kanan, N, Meenakshisundaram M and Johnson R (2009). Removal of Azure A from Aqueous solution by CAC and New Activated carbon Form Orange peels And Lemon Peel. Electronic Journal Environmental, Agricultural and Food Chemistry, 8(8), pp 574-583.

[7] Ladhe U. V., Wankhede S. K., Patil V. T. and Patil P. R. (2011). Adsorption of erichrome black t from aqueous solutions on activated carbon prepared from mosambi peel, Journal Applied Science Environmental Sanitation. 6(2), pp 149-154.

[8] Ladhe U. V., Wankhede S. K., Patil V. T. and Patil P. R. (2011), Removal of Erichrome Black T from Synthetic Waste Water by Cotton Waste. E- Journal of Chemistry, 8(2), pp 803-808

[9] Ladhe U. V., Wankhede S. K., Patil V. T. and Patil P. R. (2011). Removal of Erichrome Black T from synthetic wastewater by activated Nilgiri leaves. Journal of Chemical and Pharmaceutical Research. 3(2), pp 670-675.

[10] Özer and G. Dursun (2007), Removal of Methylene Blue from Aqueous Solution by Dehydrated Wheat Bran Car-bon, Journal of Hazardous Materials, 146 (1-2), pp.262-269

[11] Singh Vinay K., Singh Ravi S., Tiwari Prem N., Singh Jai K., Gode Fethiye, Sharma Yogesh C. (2010), Removal of Malathion from Aqueous Solutions and Waste Water Using Fly Ash, J. Water Resource and Protection, 2, pp 322-330.

[12] Pavan F.A., Mazzocato A.C., Gushikem Y. (2008), Removal of Methylene Blue dye from aqueous solutions by adsorption using yellow passion fruit peel as adsorbent, Bioresourse Technology. 99, pp. 3162-3165.

[13] Khattri, S D and Singh M K (2000). Colour removal from synthetic dye wastewater using a bioadsorbent. Water, Air and Soil Pollution, 120, pp283-294.

[14] Mas Rosemal H. Mas Haris and Kathiresan Sathasivam (2009), The removal of methyl red from aqueous solutions using banana pseudostem fibers, American Journal of Applied Sciences 6 (9), 1690-1700.

[15] McKay, G., Otterburn, M.S. and Aga A.J (1985), Fuller's earth and fired clay as absorbents for dyestuffs external mass transport processes during adsorption, Water, Air and Soil Pollution. 24, pp 307-322. 